\title{
Conservación y restauración de un tocado atacameño del sitio Solcor-3, San Pedro de Atacama, norte de Chile
}

\author{
Carolina Morales-Nilo
}

Resumen: En la colección de tocados cefálicos prehispánicos asociados a contextos funerarios del Instituto de Investigaciones Arqueológicas y Museo R.P. Gustavo Le Paige (I.I.A.M.), San Pedro de Atacama, existe un tocado atacameño poco usual conformado por una banda afelpada y un casquete cuadrado. El presente artículo expone los procesos de documentación, diagnóstico y tratamiento de conservación aplicado a este tocado atacameño, procedente del fardo funerario de un individuo de la tumba 112 del sitio Solcor 3 , asociado a la fase de influencia del estado Tiwanaku en San Pedro de Atacama.

Palabras clave: Tocado Prehispánico; San Pedro de Atacama; Solcor-3; Conservación; Textil.

\section{Conservation and restoration of an atacamenian headdress of the Solcor-3 site, San Pedro de Atacama, northern Chile}

\begin{abstract}
In the collection of Prehispanic headdresses associated to funerary contexts of the Instituto de Investigaciones Arqueológicas y Museo R.P. Gustavo Le Paige (I.I.A.M.), San Pedro de Atacama, an unusual Atacamenian specimen constituted by a velvet band and a square crown was found. The present article describes the documentation, diagnostic and conservation treatment applied to this headdress, recovered from the funerary bundle of an individual from tomb 112 of the Solcor-3 site, associated with the Tiwanaku state influence in San Pedro de Atacama.
\end{abstract}

Key words: Prehispanic headdress; San Pedro de Atacama; Solcor-3; Conservation; Textile.

\section{Conservação e restauro de um toucado Atacameno do sítio Solcor-3, São Pedro de Atacama, Norte do Chile}

Resumo: Na colecção de toucados cefálicos pré-hispânicos associados a contextos funerários do Instituto de Investigações Arqueológicas, existe um toucado Atacameno pouco usual constituído por uma banda felpuda e um gorro quadrado. O presente artigo apresenta os processos de documentação, diagnóstico e tratamento de conservação aplicado a este toucado Atacameno, procedente do espólio funerário do individuo da tumba 112 do sítio Solcor-3, associado à fase de influência do estado Tiwanaku, em São Pedro de Atacama.

Palavras-chave: toucado pré-histórico, São Pedro de Atacama, Solcor-3; Conservação; Têxtil 
Introducción: Gorros con superficie afelpada o similivelours

El tocado ha representado uno de los elementos más distintivos entre las diferentes piezas del traje andino. Sobre la base de investigaciones arqueológicas, Berenguer (2006:63) afirma que: "La variabilidad en los atuendos no es sino la propia diversidad de las sociedades andinas, vista a través de una de sus manifestaciones culturales más expresivas. La cabeza - como el punto más prominente y visible del cuerpo- constituyó el lugar privilegiado para expresar mucho de esta diversidad. "Vestir" la cabeza fue un recurso simbólico para señalar importantes distinciones en el campo político, social, económico, étnico y de género". Este hecho se replica en las sociedades prehispánicas del norte de Chile donde la extrema aridez ambiental del Desierto de Atacama ha permitido la conservación y recuperación de las prendas de vestir procedentes de ajuares funerarios.

El repertorio de tocados en el área atacameña fue señalado por Latcham (1938) en su trabajo sobre las culturas arqueológicas del Desierto de Atacama indicando, entre otros hallazgos, gorros policromos semiesféricos con superficie similar al terciopelo, también conocidos como simili-velours. De acuerdo a D'Harcout (citado en Latcham 1938: 285) esta clase de tocado se encuentra desde el lago Titicaca hasta el norte de Chile y el sur del Perú, donde los dos centros de influencia cultural habrían sido Tiwanaku e Ica-Nazca. En cuanto a la técnica, se menciona que para generar una superficie aterciopelada se elabora un tejido de fondo neutro hecho a aguja en técnica de anudado en el que se incorporan hebras- gruesas y poco torcidas- que conforman el pelo. Estas mechas policromas se agregan al tejido en el momento en que se forma y se cierra el nudo a modo de herradura para luego cortarlas a un largo de 4 ó 5 mm (Latcham 1938: 285-286).

En la misma línea de estudio, Lindberg (1963) observa los tejidos y adornos de ajuares funerarios de los sitios arqueológicos Quitor 2, 5 y 6 de San Pedro de Atacama, identificando una clase de tocado como tipo mohair con forma de fez turco. La autora describe la técnica de confección como una superficie anudada de lana fina tejida en forma circular en la que se entrelazan mechones de piel de vicuña de $5 \mathrm{~cm}$ en cada nudo (Lindberg 1963: 198).

Otra variante formal en la técnica de inserción de mechas en tocados atacameños es observada por Rojas y Hoces de la Guardia (2000: 227) )[Figura 1] para el gorro que es parte del ajuar funerario de un individuo del sitio Coyo Oriente ( $N$ * 5382.2). Las investigadoras describen a la pieza como "un hermoso gorro rojo afelpado sobre la cabeza, de estructura base en trenzado vegetal y una capa exterior en anillado y mecha..." (Rojas y Hoces de la Guardia 2000: 227) [Figura 1]. Es significativo señalar que, entre las tres prendas textiles que envolvían el cuerpo de este hombre atacameño, las autoras destacan la túnica exterior como un tejido muy fino y de una riqueza técnica e iconográfica única que harían referencia a una cultura foránea, de modo que la pren- da habría sido creada para un personaje de alta jerarquía (Rojas y Hoces de la Guardia 2000: 231). Estos antecedentes contextuales son significativos en el marco del presente trabajo ya que el tocado del individuo de Coyo Oriente comparte varios rasgos técnicos con el objeto de estudio.

Otra referencia de textiles tradicionales con superficies

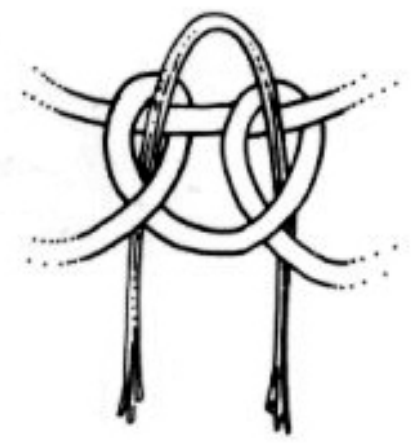

Figura 1. Ilustración de la técnica de malla anillada simple con incorporación de pelo (Bravo 1993).

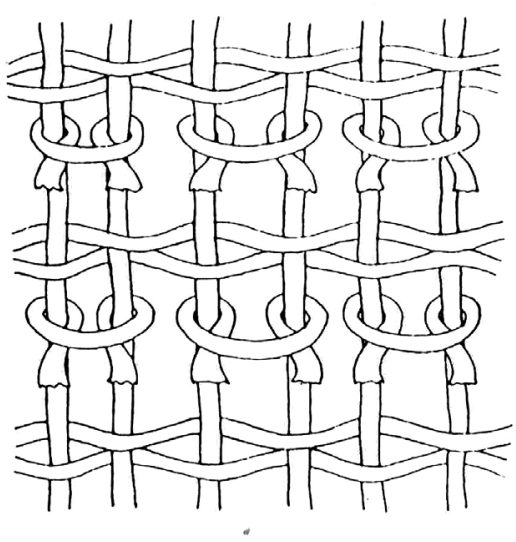

Figura 2. llustración de nudo turco o simétrico (Harris 2004).
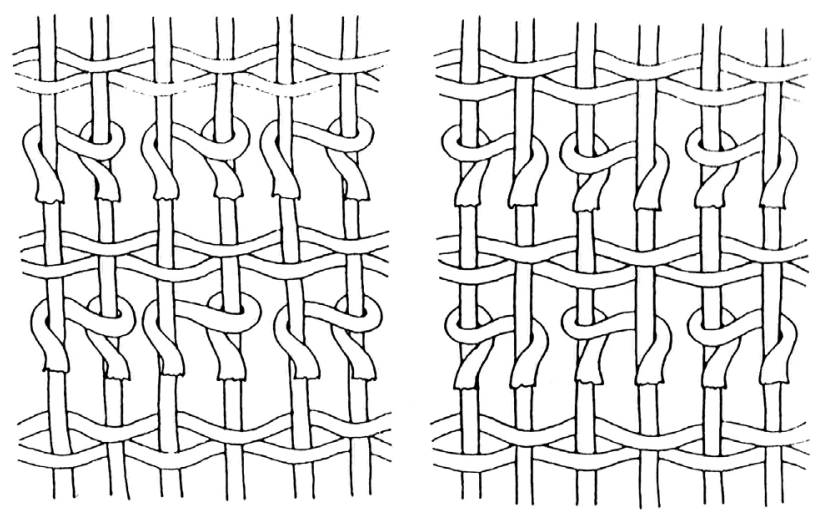

Figura 3. Ilustración de nudo persa o asimétrico (Harris 2004). 
afelpadas se relaciona con la confección de alfombras en Oriente. Estas fueron tejidas en una franja que corresponde desde España y norte de África hasta India y China y muchas de las sociedades tejedoras de alfombras estuvieron vinculadas al Islam en alguna etapa importante de su historia. Estos objetos tuvieron diversos usos, ya sea para cubrir murallas y pisos, como alfombras de oración, sillas de montar, bolsas y cojines (Harris 2004:28).

Las alfombras de pelo están hechas con pequeñas mechas que se sujetan a la urdimbre de una estructura de base a través de nudos generando una superficie densa. Los nudos más conocidos son el simétrico o nudo Turco [Figura 2] y el asimétrico o nudo Persa [Figura 3].

Sin embargo, las alfombras de pelo se diferencian técnicamente del tocado en estudio tanto por sus estructuras textiles de base como por la manera en que se insertan los pelos a esta estructura. Respecto a este tema, Seiler-Baldinger (1994: 105) expone una gran diversidad de técnicas de ornamentación clasificadas de acuerdo a la técnica del tejido de base, entre las que se mencionan tejidos de maIla, tapicería, faz de urdimbre, gasa vuelta, entre otros.

\section{Banda cefálica afelpada con casquete cuadrado}

\section{Descripción general}

El gorro de la tumba 112 de Solcor-3 presenta dos estructuras independientes: por un lado está la banda cefálica, conformada por una estructura cilíndrica interior de trenzado vegetal de 14 cabos [Figura 4] y por una cinta exterior de textura afelpada tejida en anillado simple con hilo estructural y mecha roja de $1 \mathrm{~cm}$ de largo [Figuras $5 a$ y $5 \mathrm{~b}$ ]. El diámetro de esta banda cilíndrica disminuye en su parte superior, pasando de $57 \mathrm{~cm}$ en la base a $50 \mathrm{~cm}$ en la cúspi-

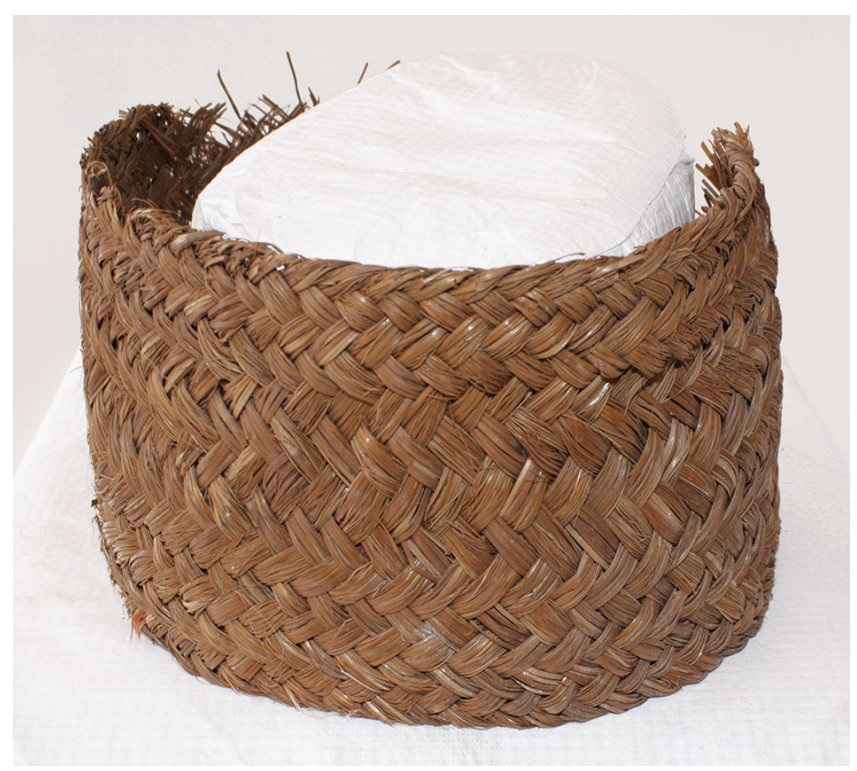

Figura 4. Estructura interior de la banda cefálica compuesta por un trenzado vegetal de 14 cabos (Morales, 2012).

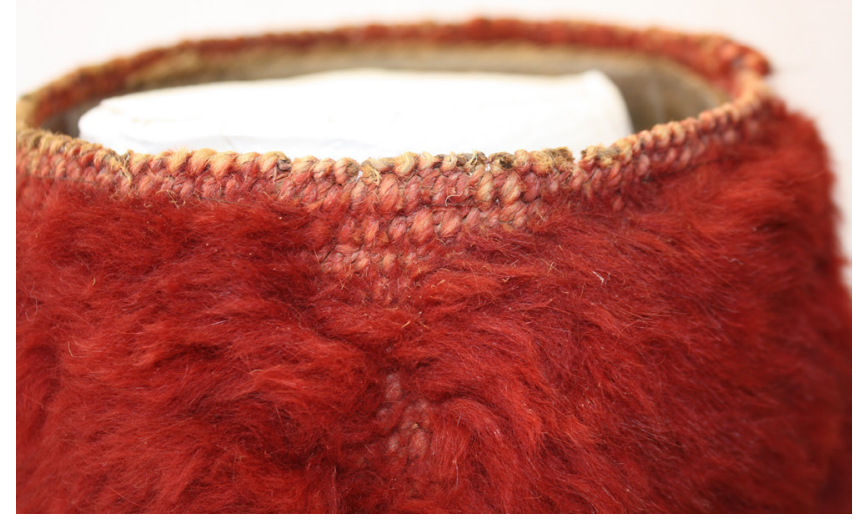

Figura 5a. Detalle del borde de la banda afelpada (Morales, 2012).

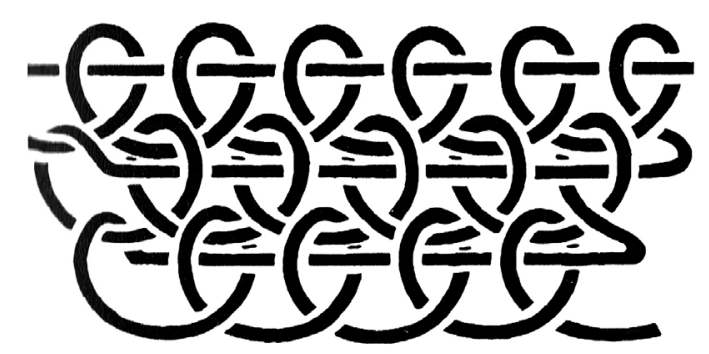

Figura 5b. llustración del tejido de base de la banda afelpada: malla anillada simple con hilo estructural (Seiler-Baldinger, 1994).

de, con una altura de 10,5 cm. En una intervención anterior realizada en el año 2006, el cintillo vegetal fue consolidado por anverso y reverso con una película de Mylar@ (tereftalato de polietileno) a través de puntadas.

Por otra parte, el gorro consta de un tejido de fibra de camélido policromo de 14 x $14 \mathrm{~cm}$ confeccionado en anudado (nudo de doble enlace simétrico) y configurado por siete cuadrados concéntricos que generan los siguientes campos de colores (desde el centro hacia los bordes): amarillo ocre, rosa, celeste, verde musgo, amarillo ocre, rosa y verde musgo [Figura 6]; este tejido fue montado sobre una almohadilla de tela durante el tratamiento de restauración en el 2006. Al analizar la progresión del tejido se registró que en los cuatro cuadrados interiores las aristas aumentan en $2 \mathrm{~cm}$; en los dos siguientes, en 1,5 cm; y en el último, más externo, en $1 \mathrm{~cm}$. Además, se observó que a partir del cuarto cuadrado se tejen nudos adicionales en los vértices de modo que se generan pequeñas puntas, lo que podría sugerir que habría una similitud con la técnica de confección de los gorros de cuatro puntas frecuentes en enterramientos del extremo norte de Chile (Sinclaire 1998; Berenguer 2006 ). La terminación de la orilla del casquete se realiza con una corrida de anudado en color amarillo ocre. Esta fina superficie textil - con una densidad de 36 nudos por $\mathrm{cm}^{2}$ - fue encapsulada entre dos soportes de crepelina amarillo ocre en la restauración anterior. Al interior del embalaje que contiene el gorro se encuentran también fragmentos de plumas rojas, levemente decoloradas. En el marco del presente estudio, se encontraron otros 


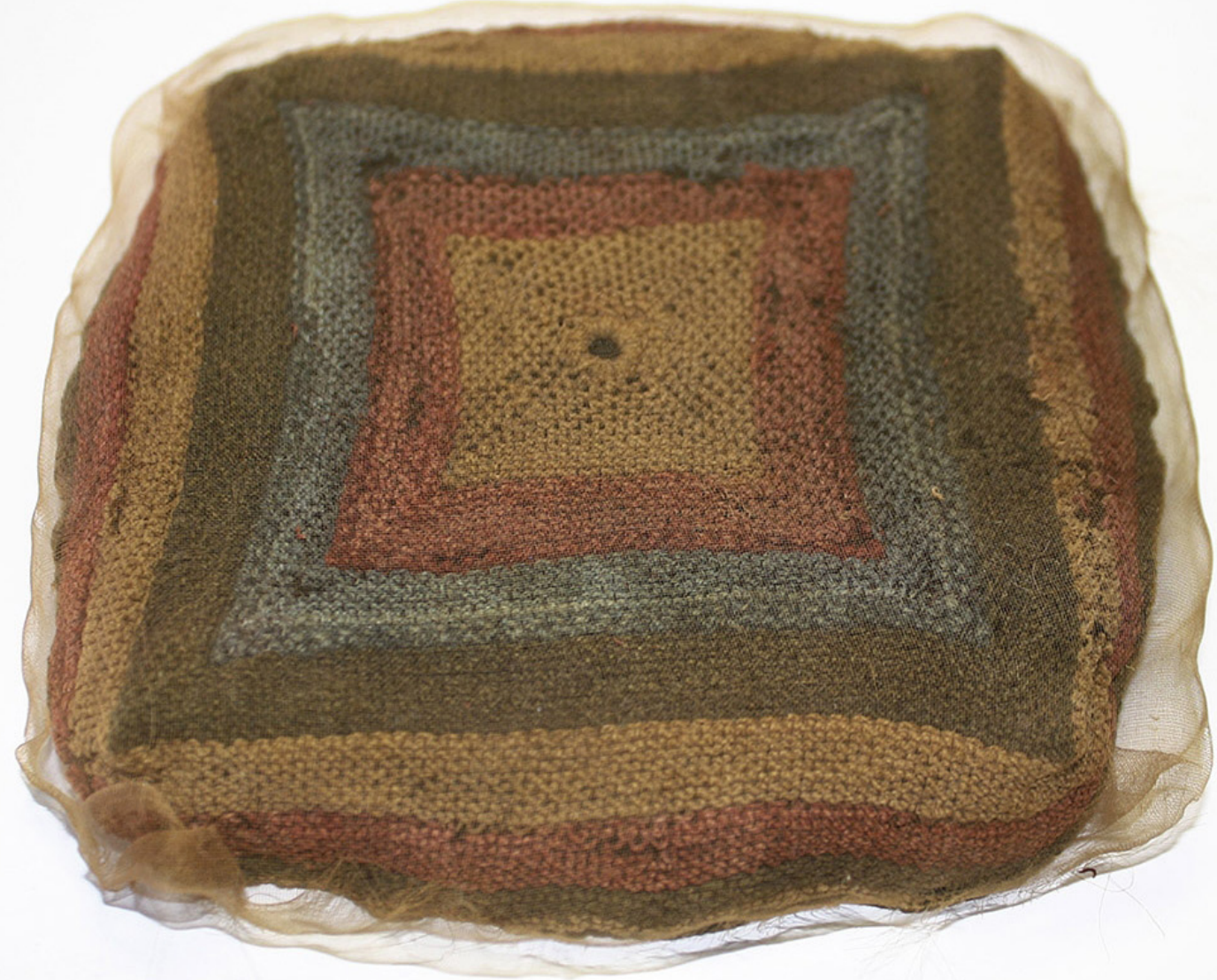

Figura 6. Casquete tejido en malla anudada con diseño de cuadrados concéntricos (Morales 2012).

fragmentos de atados de plumas rojas y blancas también asociados a la tumba 112 [Figura 7].

El proceso de documentación de la pieza en estudio fue fundamental para dilucidar dos cuestiones principales: indagar por qué las estructuras de banda afelpada y cas-

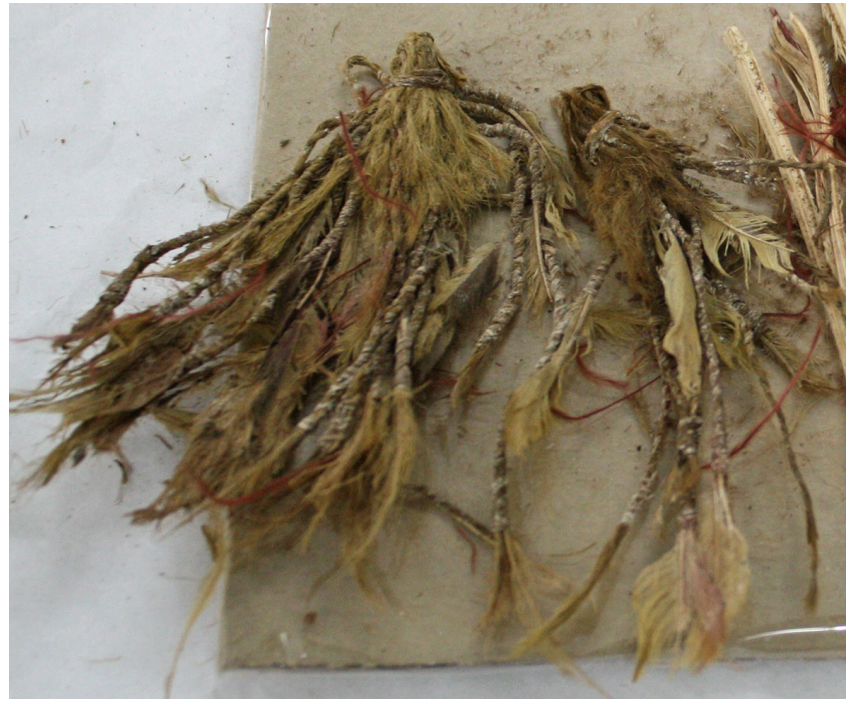

Figura 7. Detalle de fragmentos de atados de plumas asociados al tocado (Morales, 2012). quete se encontraban separadas y, en paralelo, cuál habría sido la forma original de la banda en función de un casquete evidentemente cuadrado. Para lo anterior se recopiló documentación arqueológica acerca del individuo de la tumba 112 del sitio Solcor-3 para lo cual se contactó a investigadores y otros integrantes de tal excavación. Del mismo modo, se revisaron las fichas asociadas al objeto facilitadas por la Unidad de Conservación del I.I.A.M.

\section{Documentación}

Solcor-3, ubicado en los límites del ayllu ${ }^{1}$ de Solcor, es uno de los más grandes cementerios prehispánicos utilizados durante el Horizonte Medio en San Pedro de Atacama. En 1983, Bravo y Llagostera dirigen las excavaciones del sitio encontrando 153 cuerpos distribuidos en 93 tumbas (Bravo y Llagostera 1986: 323) que fueron ampliadas posteriormente a 117 tumbas (Llagostera et al. 1988: 70). El cementerio estuvo en uso durante los años 400-900 d.C., observándose dos fases de ocupación: una pre-Tiwanaku y otra posterior, que muestra evidencia de la influencia Tiwanaku (Llagostera et al. 1988). Los objetos tiwanakotas encontrados en Solcor-3 están vinculados principalmente al complejo alucinógeno, que para este sitio, se caracteriza por "(...) una bolsa textil que contiene una tableta, un tubo, una cucharilla, y una o dos bolsas de cuero con los polvos alucinógenos" (Llagostera et al. 1988: 72). 


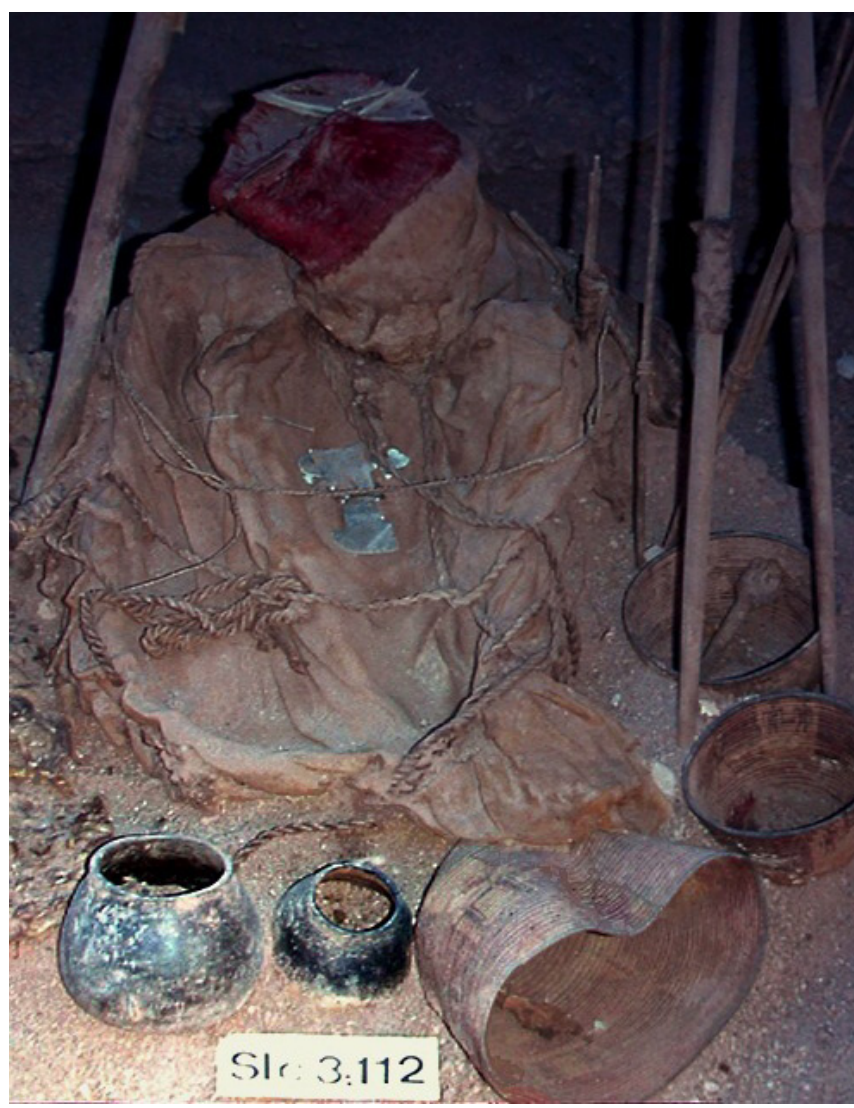

Figura 8a. Individuo de la tumba 112 en el sitio Solcor-3.

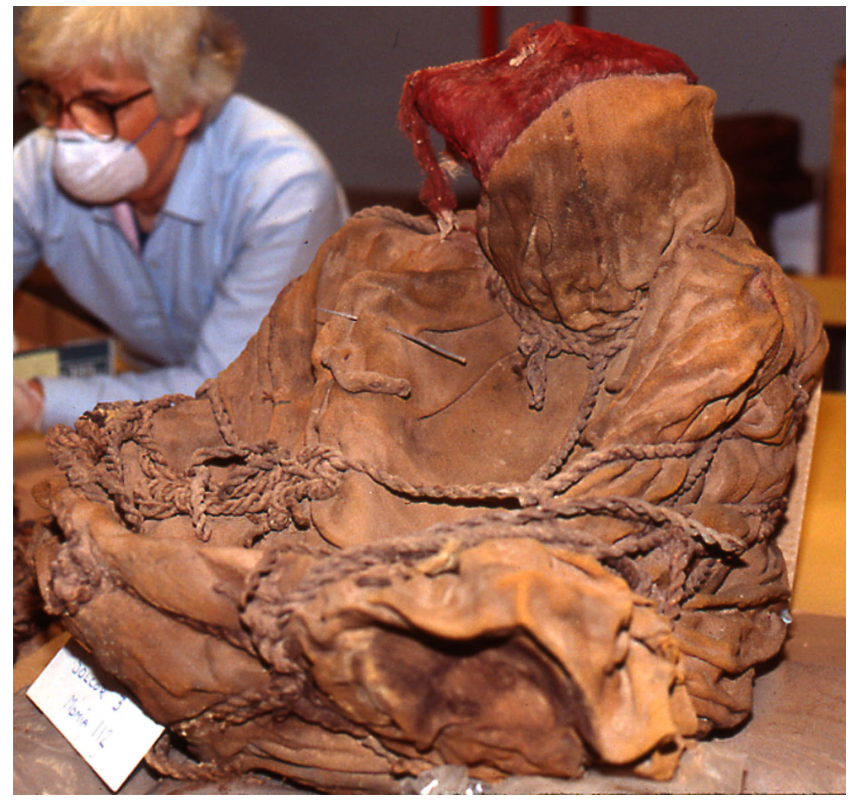

Figura 8b. Individuo de la tumba 112 traslado al I.I.A.M. Detalle del tocado rojo sobrepuesto al fardo funerario.

La tumba 112 del sitio Solcor-3 pertenece a la fase de influencia Tiwanaku. Se identifica el cuerpo como de un individuo probablemente varón por la presencia de arco y hacha entre sus ofrendas. La descripción del ajuar funerario

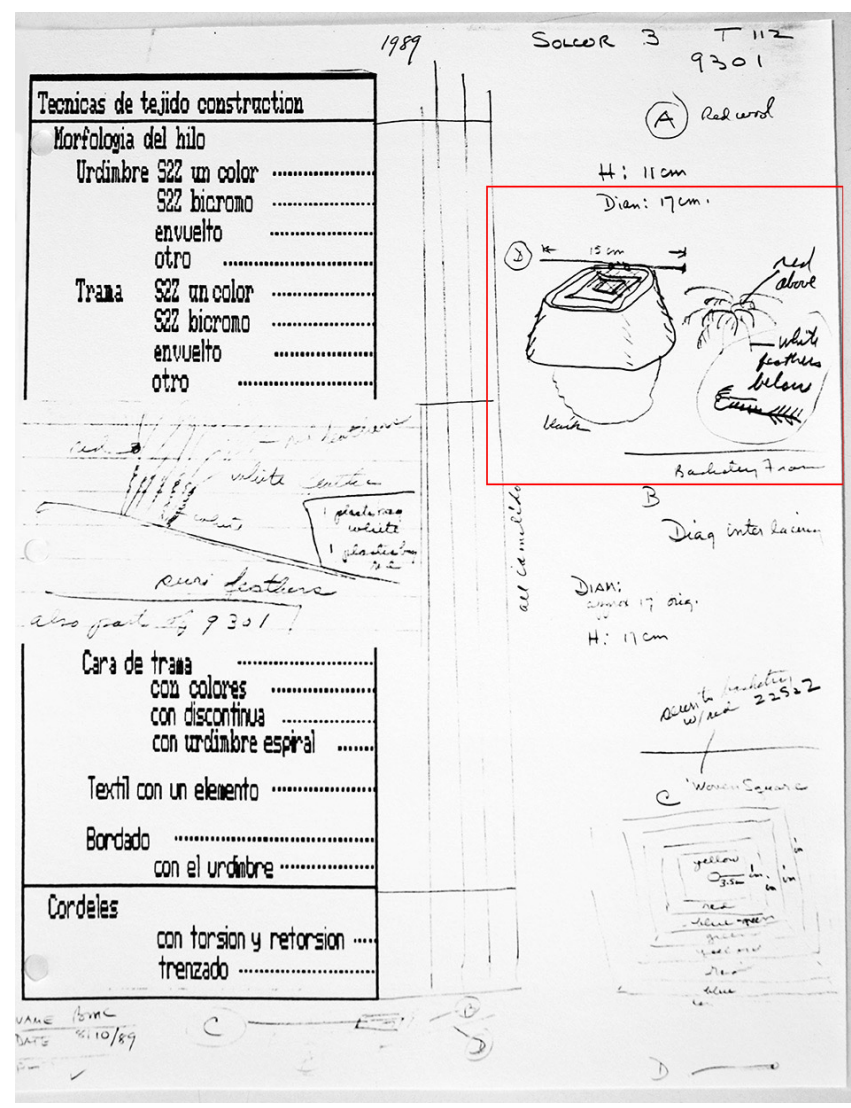

Figura 9. Ficha técnica del tocado elaborada por Barbara Conklin en 1989 (Registro I.I.A.M.).

se centra en el equipo psicotrópico y en otros artefactos como tres canastos y dos vasijas ovoides, sin indicar detalles acerca de los atuendos de la momia (Llagostera et al. 1988: 101).

A partir de la comunicación con los arqueólogos responsables de la excavación en Solcor-3 (Llagostera y Torres, com. personal, 2012) se accedió al registro visual del cuerpo ${ }^{2}$ en sitio y una vez que éste fue trasladado al laboratorio de la Unidad de Conservación del I.I.A.M. [Figuras 8a y 8b]. Si bien la fotografía del momento de su hallazgo da cuenta de un tocado volumétrico con aristas marcadas, es necesario considerar que su forma podría haberse alterado producto de las condiciones de entierro. Las escasas imágenes recopiladas no permiten distinguir el casquete con claridad ya que son tomas frontales del objeto; sin embargo, evidencian el desprendimiento de plumas rojas y blancas desde la copa del gorro.

En la búsqueda de información contextual de la tumba 112 se revisó el libro de registros del I.I.A.M. en el que se hace mención a la banda roja afelpada y su estructura vegetal, pero los autores no describen el casquete policromo. Para contrastar lo anterior, se consultó a un miembro del equipo de excavación de la tumba 112 (Tomás Cruz, com. personal, 2012) quien recordó que, efectivamente, el casquete le pertenecía a la banda afelpada roja, lo que se confirmaría más adelante a través de la revisión de nuevos datos. 
Otro documento que proporcionó importantes antecedentes acerca de los atributos formales y materiales del objeto de estudio es la ficha técnica realizada por la investigadora Barbara Conklin en 1989 [Figura 9]. En ella, se ilustra un tocado de base trapezoidal con una superficie afelpada coronado por un tejido cuadrado de lana de camélido que presenta siete cuadrados concéntricos con la misma secuencia de colores descrita previamente. La autora esquematiza también el modo como se incorporan las plumas de suri sobre el casquete, detallando que las plumas rojas van por encima de las blancas. En 2003, la arqueóloga Carolina Agüero desarrolla una nueva ficha técnica del artefacto en la que clasifica la pieza como un gorro fez afelpado, es decir, sugiere un volumen que reduce su diámetro en la parte superior al igual que un cono truncado.

El informe de restauración del tocado en estudio realizado en 2006 sería un documento clave para entender tanto aspectos originales de manufactura como las alteraciones presentes en la pieza. A partir del registro fotográfico del objeto previo a dicha intervención se comprobó nuevamente que la banda cefálica estaba coronada por un casquete policromo; aún más, se observaron los hilos desprendidos que aparentemente unían la banda cefálica al casquete [Figura 10]. En cuanto al estado de conservación, el mencionado informe reporta las siguientes alteraciones y deterioros: deformación estructural, suciedad de polvo y sales, sustancias proteicas en la superficie, pérdida en la estructura vegetal y desprendimiento de la copa. Se informa también acerca del tratamiento de restauración aplicado de acuerdo a los siguientes procedimientos: 1) desinfección en cámara fría por 48 horas, 2) aspirado y barrido con

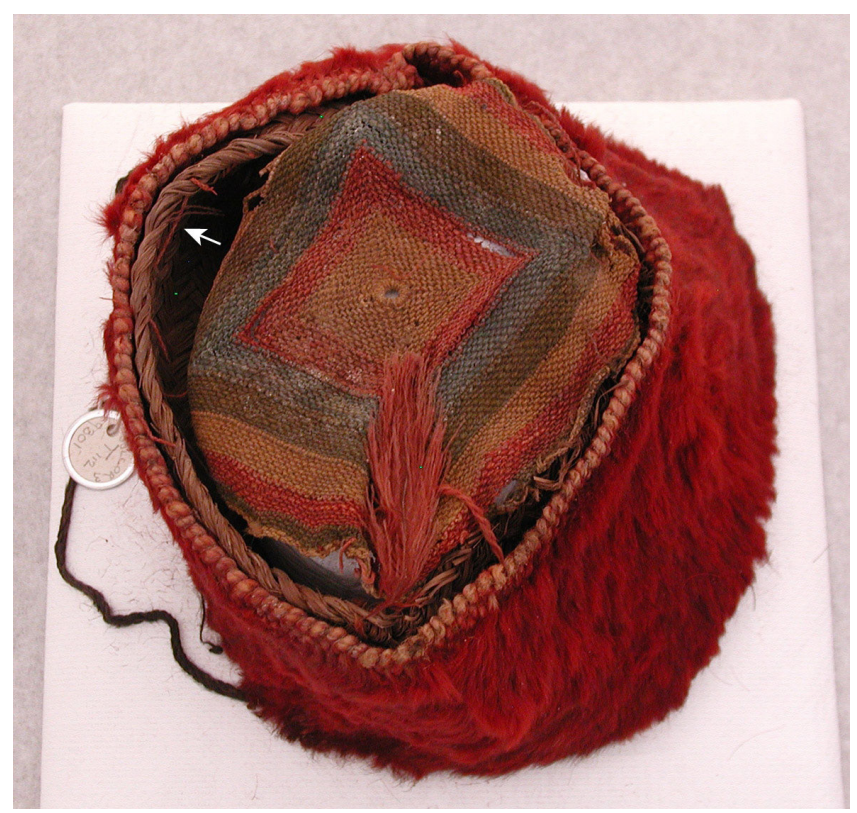

Figura 10. Registro fotográfico previo intervención realizada en 2006. Detalle de los hilos desprendidos que unían las estructuras del gorro (Registro I.I.A.M.).

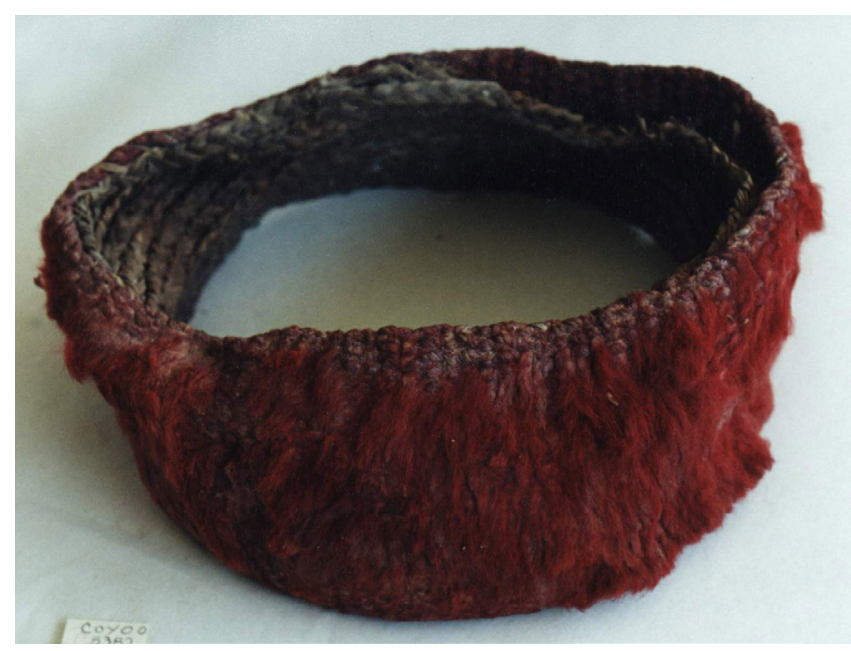

Figura 11a. Gorro Coyo Oriente № 5382.2 (Hoces de la Guardia 2000).

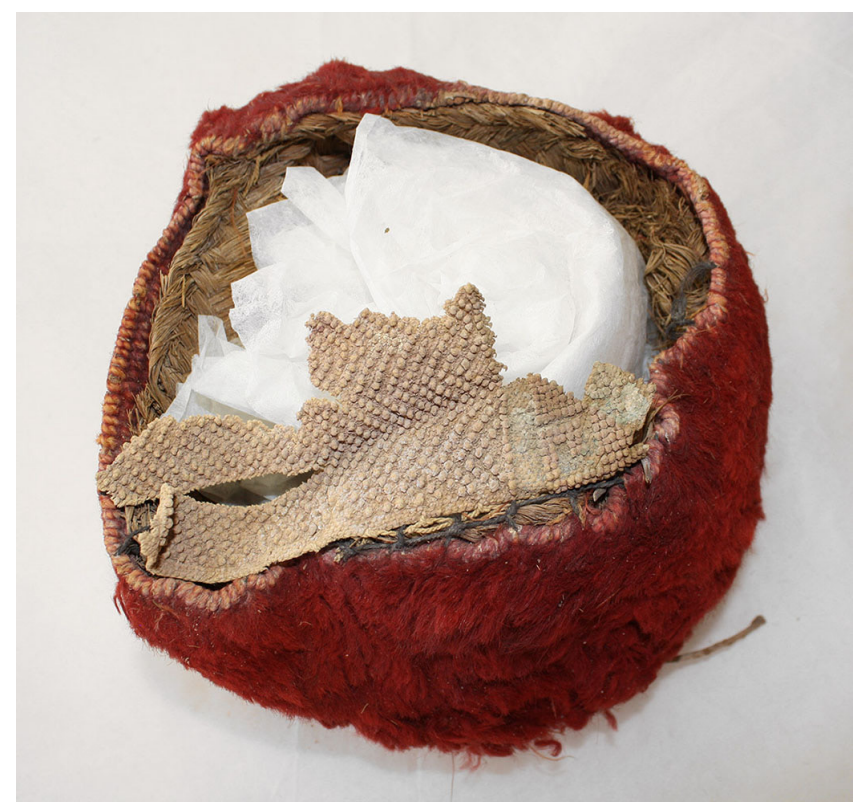

Figura 12a. Gorro Coyo Oriente № 3934. Banda cefálica afelpada con fragmento de casquete (Morales 2012).

pinceles, 3) lavado de la copa en solución desmineralizada y jabón neutro, 4) secado sobre molde con forma original (4 puntas), 5) humidificación por tres días para recuperar la forma original, 6) consolidación del casquete con soporte de crepelina y 7) consolidación del tejido vegetal con una solución de Paraloid@ (copolímero de metil metacrilato y butil acrilato) ${ }^{3}$ en acetona, y encapsulamiento entre láminas de Mylar@.

Con el fin de identificar un patrón formal de esta clase de tocado se buscaron especímenes similares al gorro de la tumba 112 de Solcor-3 en la colección. De un universo de 143 piezas se reconocieron dos gorros del sitio Coyo Oriente con atributos afines: el No 5382.2, mencionado anteriormente, y el No 3934 . 


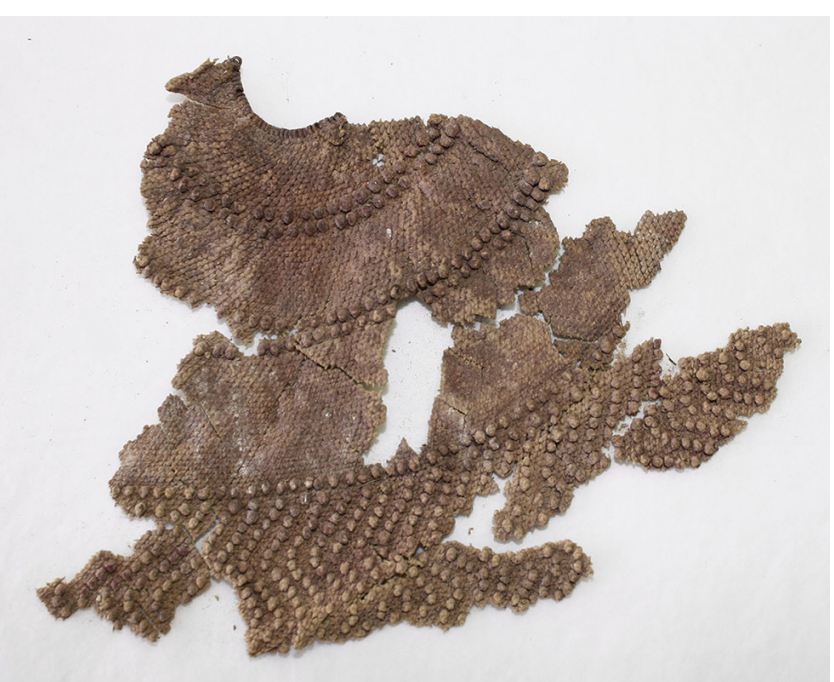

Figura 12b. Detalle del casquete circular tejido en anillado simple. Gorro Coyo Oriente № 3934 (Morales 2012).

El primero consta de una banda afelpada roja con estructura vegetal interior circular levemente deformada [Figura 11a]. El segundo gorro es igualmente interesante ya que permite proponer una relación formal entre la banda cefálica y el tejido que la corona; en este caso, el casquete presenta una superficie circular tejida en anillado simple que coincide con una banda cefálica cilíndrica, hoy deformada [Figuras 12a y 12b]. Por lo tanto, los gorros Solcor 3, tumba 112 y Coyo Oriente № 3934 son ejemplares de las dos variantes registradas para esta clase de tocado definida por la técnica de confección del casquete: el anudado (knotting) o el anillado simple (looping). Lo anterior constata la misma diferenciación observada por Oakland (1994: 111) para el tipo de gorros con cintillo y casquete.

Finalmente, es interesante notar que los casquetes tejidos en técnica de anudado en los gorros con cintillo y casquete son octogonales, lo que hace suponer que los tejedores han buscado una solución para que este tejido se adapte a la circunferencia del cintillo, ya que el anudado, a diferencia del anillado simple, no permite obtener formas circulares.

A partir de la documentación recopilada y anteriormente expuesta, se concluye que en el contexto sistémico, las estructuras del gorro en estudio - banda cefálica y casquete- estaban unidas. Además, se sugiere que la forma de la banda cefálica habría sido levemente trapezoidal de modo que hubiera coincidido en su perímetro superior con el casquete cuadrado. Estas características del tocado, técnica y morfológica, pretenden ser recuperadas en el supuesto de que fueron alteradas por la intervención realizada en el año 2006.

\section{Análisis del Estado de Conservación}

La pieza de estudio se encuentra estable y está adecuada- mente embalada. Sin embargo, se observan las siguientes alteraciones en el actual diagnóstico:

\section{Alteración superficial}

1.1. Adherencias superficiales: presencia de polvo en la superficie afelpada exterior y, en mayor concentración, en las láminas de Mylar@ que consolidan el cintillo vegetal interior. La acumulación de polvo sobre el textil es abrasivo, penetra en las fibras y las corroe, además de favorecer el crecimiento de insectos (Comité Nacional de Conservación Textil 2002).

1.2. Pérdida de componentes: este deterioro se identifica en el desprendimiento total de las plumas que decoraban el tocado. De éstas, se encontraron fragmentos de los atados de plumas rojas y blancas cuya única información acerca de la técnica de manufactura se encuentra en la ficha técnica elaborada por Barbara Conklin en 1989.

\section{Alteración estructural}

2.1. La separación de las estructuras textiles que conforman el tocado- banda cefálica y casquete- no permiten visualizar la pieza en su totalidad. Esta fragmentación genera la incertidumbre de que el casquete efectivamente le pertenezca a la banda.

2.2. El cintillo vegetal interior presenta un $25 \%$ de faltante lo que debilita estructuralmente la banda cefálica.

2.3. La fragilidad de las fibras textiles está presente tanto en las fibras proteicas como en las celulósicas. Para el primer caso, la oxidación de las fibras de camélido del casquete se hace evidente a través del amarilleamiento de la superficie. En el segundo caso, es notorio el resecamiento y el brillo de las fibras vegetales del cintillo interior de la banda cefálica, cuyo deterioro se potenció luego de la aplicación de Paraloid@. Los efectos descritos son avalados por los trabajos de Kronkright y de Tworek (citados en Norton 1990: 237). El primer autor señala que algunas resinas sintéticas provocan cambio de color y rigidez en los objetos de cestería; el segundo informa que el Paraloid B-72 (resina acrílica), el Revacryl 452 (dispersión acrílica coloidal) y el Methocel A4C (pasta de metilcelulosa) generan cambios de color y textura.

\section{Alteración visual}

3.1. Se observan dobleces y arrugas en los vértices interiores del casquete producto del acomodo del tejido sobre una almohadilla estructural. Asimismo, el casquete presenta cortes y pequeños faltantes en el tejido anudado.

3.2. El soporte de crepelina ocre usado para consolidar la superficie anversa del casquete intensifica el efecto de 


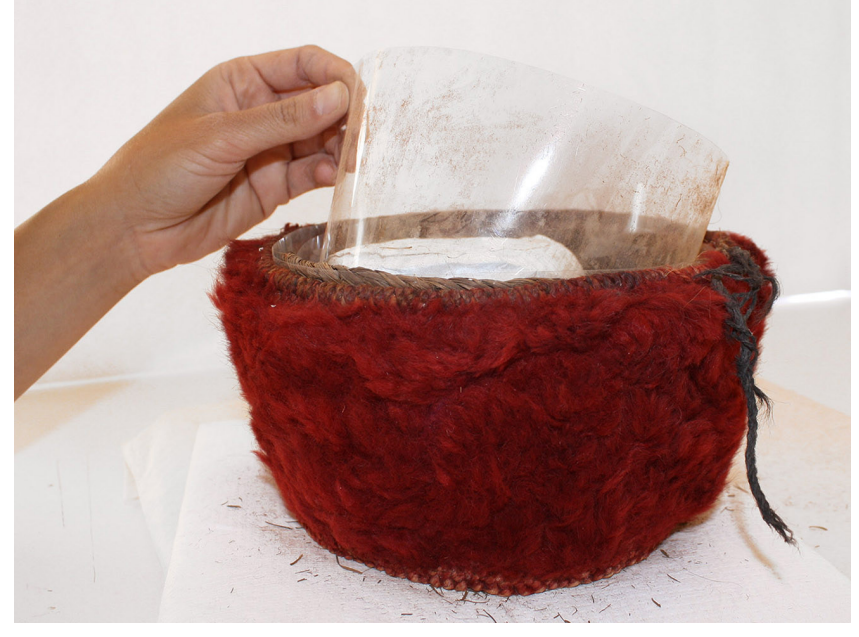

Figura 13. Retiro de las láminas de Mylar para evitar la adherencia del polvo en suspensión en la pieza (Morales 2012).

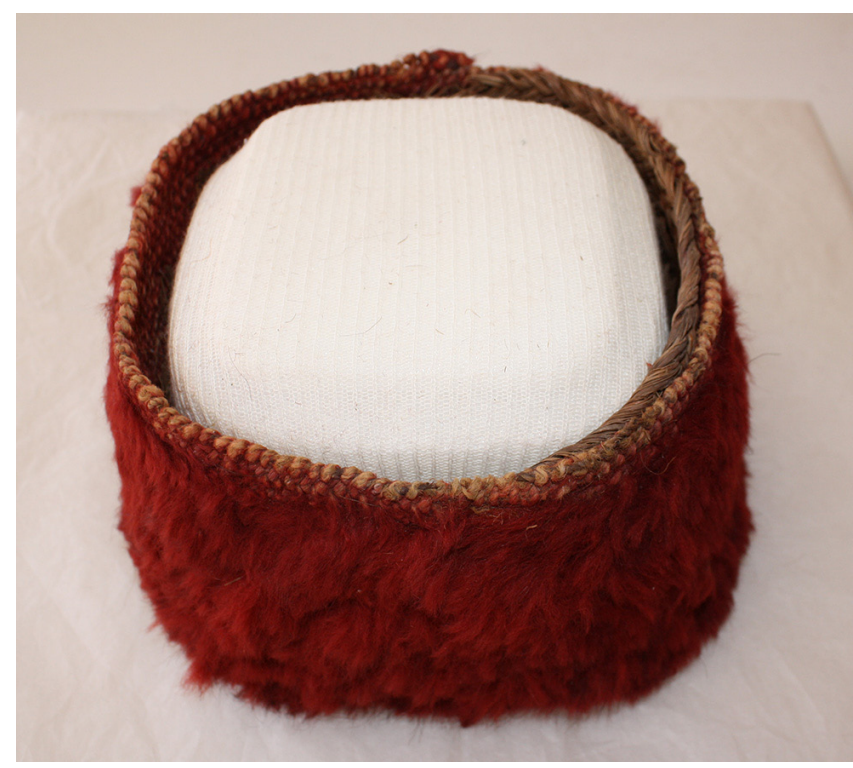

Figura 14. Instalación de un molde de Ethafoam ligeramente trapezoidal al interior de la banda cefálica. (Morales 2012).

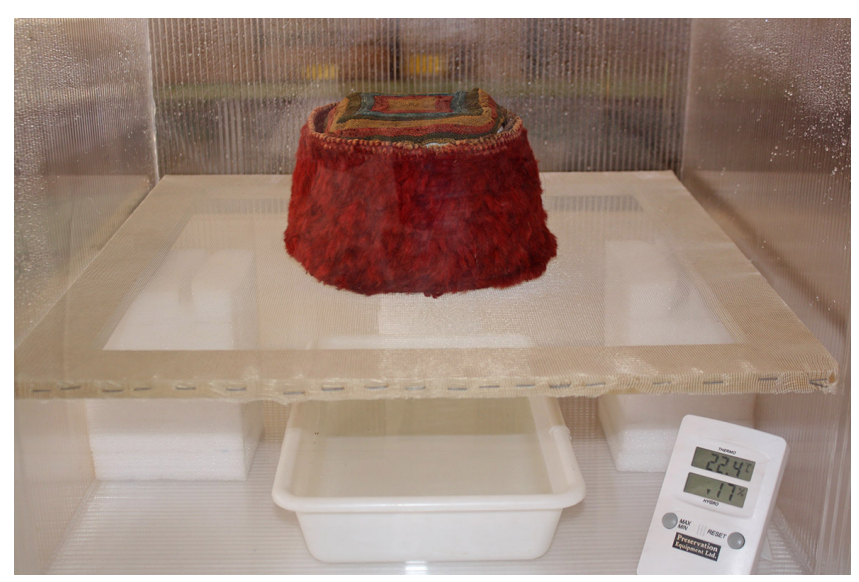

Figura 15. Ingreso de la pieza con el molde interior a la cámara de humificación (Morales 2012). amarilleamiento de las fibras de camélido producto de la oxidación, y genera una cierta distorsión de los colores actuales del textil.

Según lo expuesto en la documentación y en el análisis del estado de conservación, se propone un tratamiento orientado a: 1) evaluar los soportes incorporados al artefacto en la restauración anterior, eliminando o reemplazando aquellos que se consideren inadecuados, evitando alterar la estabilidad de la pieza, 2) hidratar las fibras textiles de la pieza para recuperar la forma original de sus partes y 3) unir el casquete a la banda cefálica para restituir la legibilidad estética del objeto.

\section{Tratamiento de Restauración}

Como medida previa a la intervención se retiraron muestras de fibras de camélido de la banda cefálica (hilado de la estructura anillada y vellón rojo de la superficie afelpada) y del casquete (hilados de color rojo, azul, verde y ocre), y muestras de fibras vegetales de la trenza plana para análisis posteriores en laboratorio (identificación de colorantes orgánicos e identificación de fibras).

\section{Retiro de soportes}

Se retiró el soporte de crepelina ocre del anverso del casquete ya que éste no permitía apreciar los colores actuales de la superficie del tejido. Este procedimiento no interfirió con la estabilidad del casquete ya que se mantuvo la crepelina de la cara reversa.

Asimismo, se retiraron las capas de Mylar@ del cintillo vegetal de la banda cefálica debido a que este plástico es electrostático y atrae el polvo en suspensión que se acumula con facilidad en climas áridos como el de San Pedro de Atacama. [Figura 13].

\section{Confección de molde}

Luego de la aspiración con baja succión de la banda afelpada y del casquete con el fin de retirar la suciedad superficial se confeccionó un molde de espuma de polietileno (Ethafoam $\odot$ ) levemente trapezoidal, con el contorno inferior $7 \mathrm{~cm}$ mayor que el contorno superior. Se forró el soporte con un jersey tubular de algodón para evitar roces de la superficie del molde con el gorro, y se instaló al interior de la banda cefálica [Figura 14].

\section{Humidificación}

Se ingresó la pieza montada sobre el molde de Ethafoam@ y el casquete sobrepuesto a la banda afelpada a una cámara de humidificación de policarbonato usando una bandeja de agua destilada como fuente de humedad [Figura 15]. Se cerró la cámara por dos días. Luego de ese período, en el que las fibras fueron humectadas a través del vapor del agua destilada, se fijó el casquete al soporte de Ethafoam® 


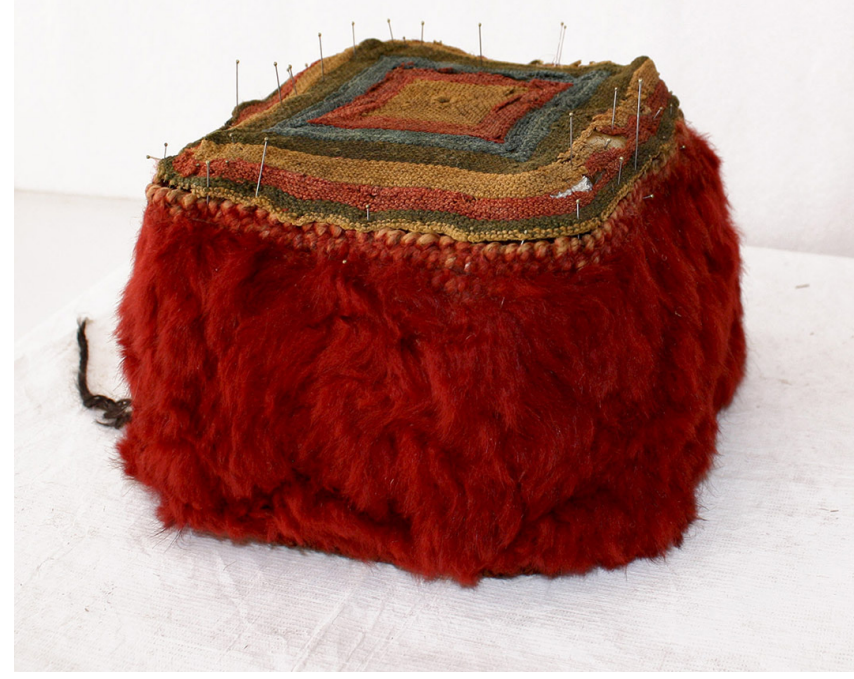

Figura 16. Fijación de la superficie del casquete al molde a través de alfileres entomológicos galvanizados (Morales 2012).

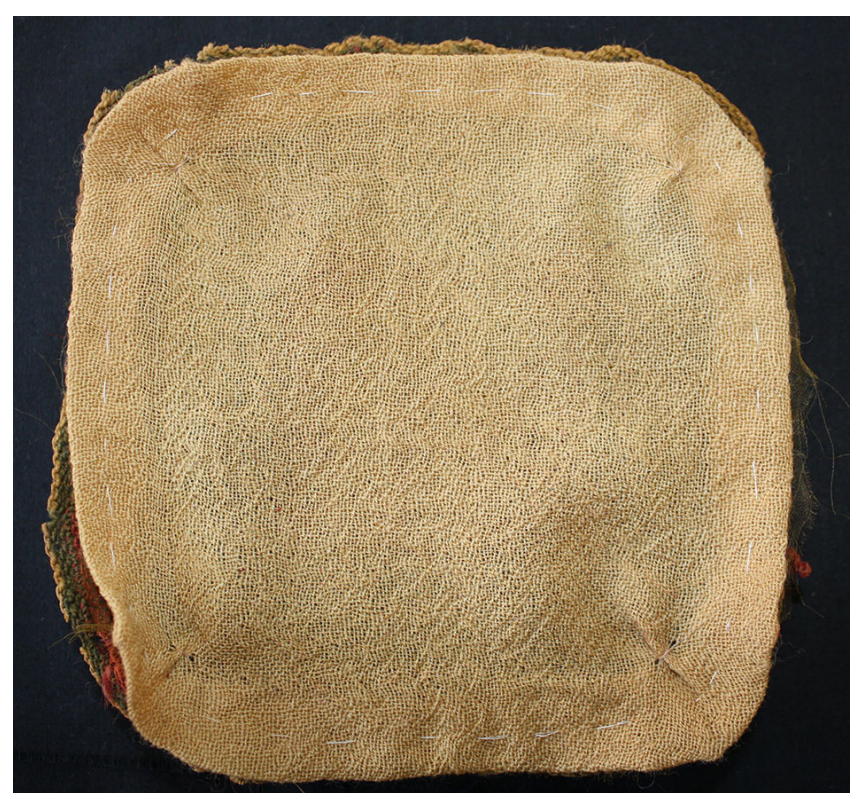

Figura 17. Soporte de etamina de lana fijado al casquete previo consolidación (Morales 2012).

usando alfileres entomológicos galvanizados ( $\left.\mathrm{N}^{\circ} 0\right)$ [Figura 16]. Se colocaron pequeñas almohadillas de espuma forrada en malla tubular de algodón para rellenar las esquinas interiores del tejido y así insinuar la prolongación de los vértices en forma de cuatro puntas. Luego se reingresó la pieza por dos días adicionales a la cámara, rociando previamente sus paredes con agua destilada ${ }^{4}$. En el quinto día, se retiró la bandeja de agua desde la cámara para que el gorro se secara lentamente durante otros dos días al interior de la cámara y así evitar que las fibras textiles sufrieran estrés a causa de los cambios bruscos en la humedad
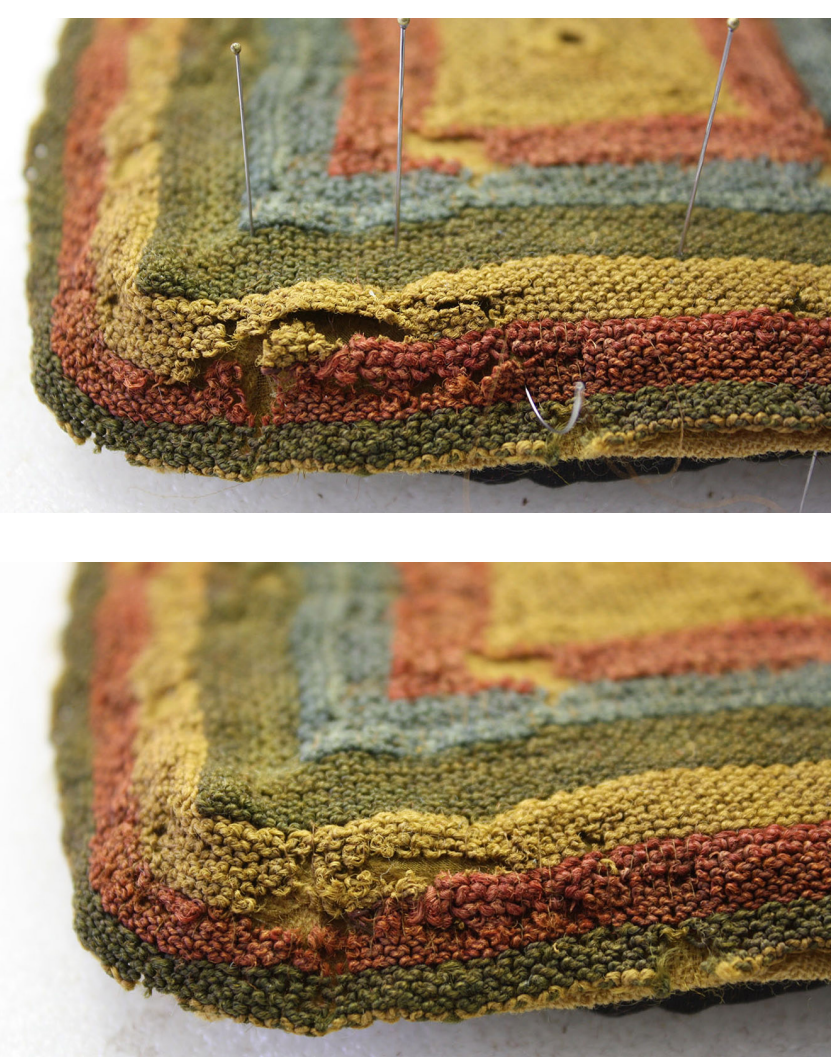

Figura 18a y b. Antes y después de consolidación del casquete a través de puntadas de couching (Morales 2012).

relativa, conllevando eventuales daños mecánicos en el material textil. Para lo anterior, se consideró la recomendación de Tímár-Balázsy (1999) en relación con el lavado de textiles históricos, quien señala que para retener la flexibilidad obtenida en las fibras lo óptimo es un ambiente con humedad relativa del $55 \%$ durante el secado.

El proceso de humidificación otorgó una forma ligeramente trapezoidal a la banda afelpada, lo que permitió que el perímetro del casquete se adaptara a los bordes de la banda.

\section{Consolidación}

Con el fin de reforzar la estructura del casquete y reintegrar las áreas faltantes era necesario incorporar un soporte en la cara reversa. Para esto se usó un tejido de lana en ligamento de tela (etamina de lana de $80 \mathrm{~g}$ ) ya que tanto la densidad como el ligamento del tejido se ajustaban a las características de la superficie textil original. Se hicieron pruebas de teñido con colorantes reactivos Lanaset $\odot$ mediante mezcla de tricromía, optando finalmente por el color amarillo ocre ya que generaba un fondo neutro para la reintegración cromática. Una vez teñido, se realizaron pinzas en las esquinas del soporte de manera que éste se adaptara a la forma del casquete cuadrangular y se fijaron ambos tejidos a través de puntadas de hilván [Figura 17]. Luego, se desprendieron progresivamente las puntadas diagonales de la restauración anterior para reemplazarlas 


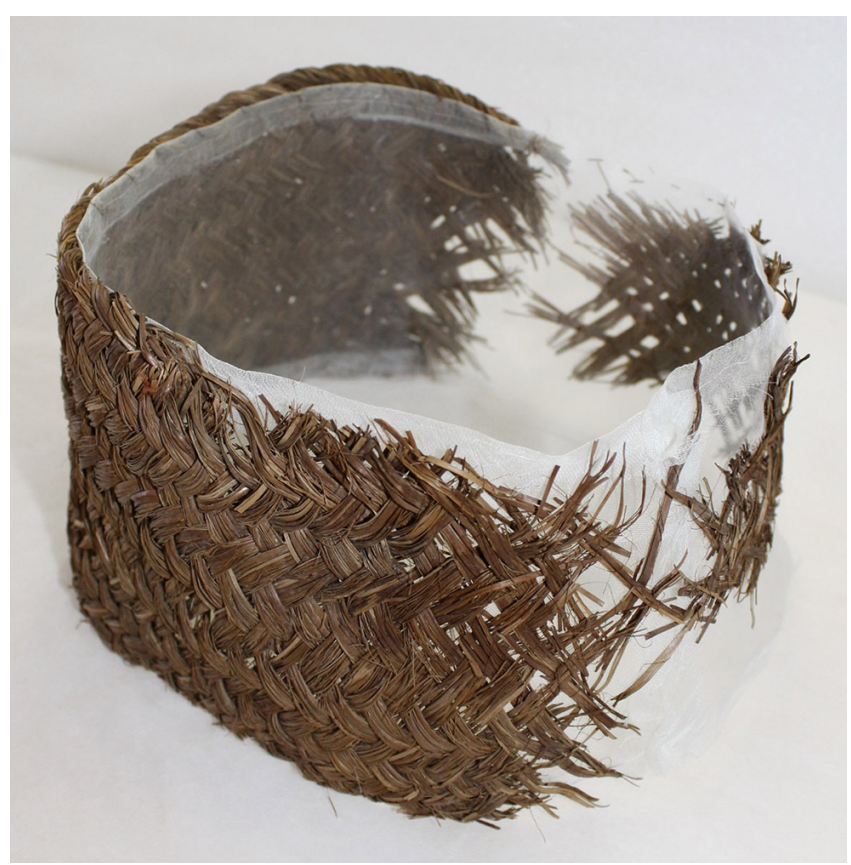

Figura 19. Consolidación del cintillo vegetal a un soporte de crepelina mediante puntadas con hilo de seda (Morales 2012).

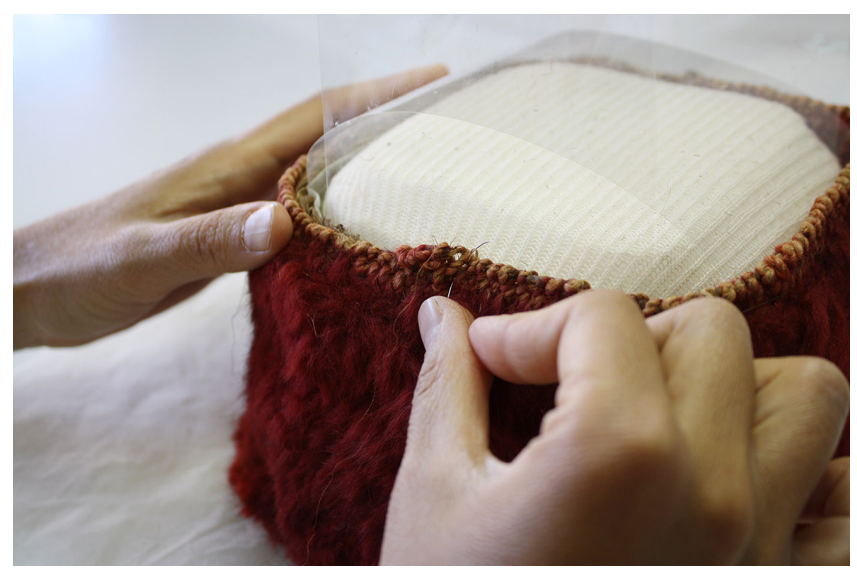

Figura 20. Unión entre las estructuras de la banda cefálica a través de puntadas con hilo de seda (Morales 2012).

por costuras de couching debido a que esta técnica es más efectiva para soportar la superficie textil, además de generar una superficie más plana. De este modo, se consolidaron las áreas faltantes y los cortes mediante puntadas de couching con aguja quirúrgica curva Kalt No1 e hilo de seda color tostado. Durante este proceso fue necesario el apoyo de una lupa ya que el tejido anudado presenta una superficie muy fina. El resultado luego de la consolidación fue una superficie textil más regular y sin arrugas en las puntas [Figura 18a y 18b].

En cuanto a la consolidación del cintillo interior de la banda cefálica se buscó un material adecuado que reemplazara el Mylar@. El nuevo soporte debiera permitir contener las fibras vegetales altamente friables sin alterar la apa- riencia del material relativo al oscurecimiento y brillo de la superficie (Norton 1990: 235). Se tomó en consideración la opción de un tratamiento sin solventes sugerido por Norton (1990: 239) quien propone el uso de un soporte de crepelina de seda o Stabiltex $\odot$ (crepelina de poliéster). De este modo, se consolidó el cintillo vegetal a una banda de crepelina de seda mediante puntadas diagonales en los perímetros superior e inferior de la estructura [Figura 19]. El área del cintillo que presentaba mayor desprendimiento de material fue reforzado con puntadas adicionales para fijar los cabos desprendidos de la trenza vegetal. Este procedimiento se realizó con la mínima manipulación posible debido al resecamiento que presentaban las fibras del entramado.

\section{Unión de estructuras}

Una vez que la banda vegetal fue consolidada se adhirió al cintillo afelpado con costuras en los bordes superior e inferior [Figura 20]. Luego, se unió el casquete a ambas estructuras de la banda a través de puntadas diagonales con hilo de seda doble. Para lo anterior, se estableció un patrón de 1,5 cm de distancia en función de pequeños agujeros observados en el borde del tejido anudado que se interpretaron como marcas de la costura original.

Finalmente, se realizó el registro fotográfico del resultado final obtenido [Figuras $21 \mathrm{a}$ y b].

\section{Conclusiones}

El presente trabajo generó un debate crítico entre arqueólogos y conservadores del I.I.A.M. en torno a la propuesta de tratamiento para la pieza en estudio, convirtiendo la instancia de intervención en una oportunidad para articular los distintos actores que habían participado en los procesos de excavación y posterior conservación de la pieza. La recopilación de documentos que registraron los antecedentes históricos y clínicos del artefacto - fichas técnicas, informes de restauración, registros fotográficos - así como la observación de especímenes similares en la colección aportaron información primordial que permitió fundamentar el tratamiento de restauración.

En esta búsqueda de recopilar datos para el análisis técnico y formal del tocado en discusión se sugiere el estudio de referentes artefactuales de otras colecciones del subárea Circumpuneña (suroeste de Bolivia, Región de Antofagasta en Chile y el Noroeste argentino) en las que podrían, eventualmente, encontrarse objetos textiles afines debido a los vínculos existentes entre poblaciones prehispánicas de estas regiones. Éstas compartieron el empleo de la técnica de mallas anilladas y redes anudadas que en los Andes alcanzó una gran diversidad de variantes según la densidad, la dirección y el tipo de enlace o nudo utilizado para tejer bolsas, redes de pesca y tocados. Es por ello que aunque comparten la técnica de la incorporación de pelos a un tejido de base, los textiles andinos se diferencian de 

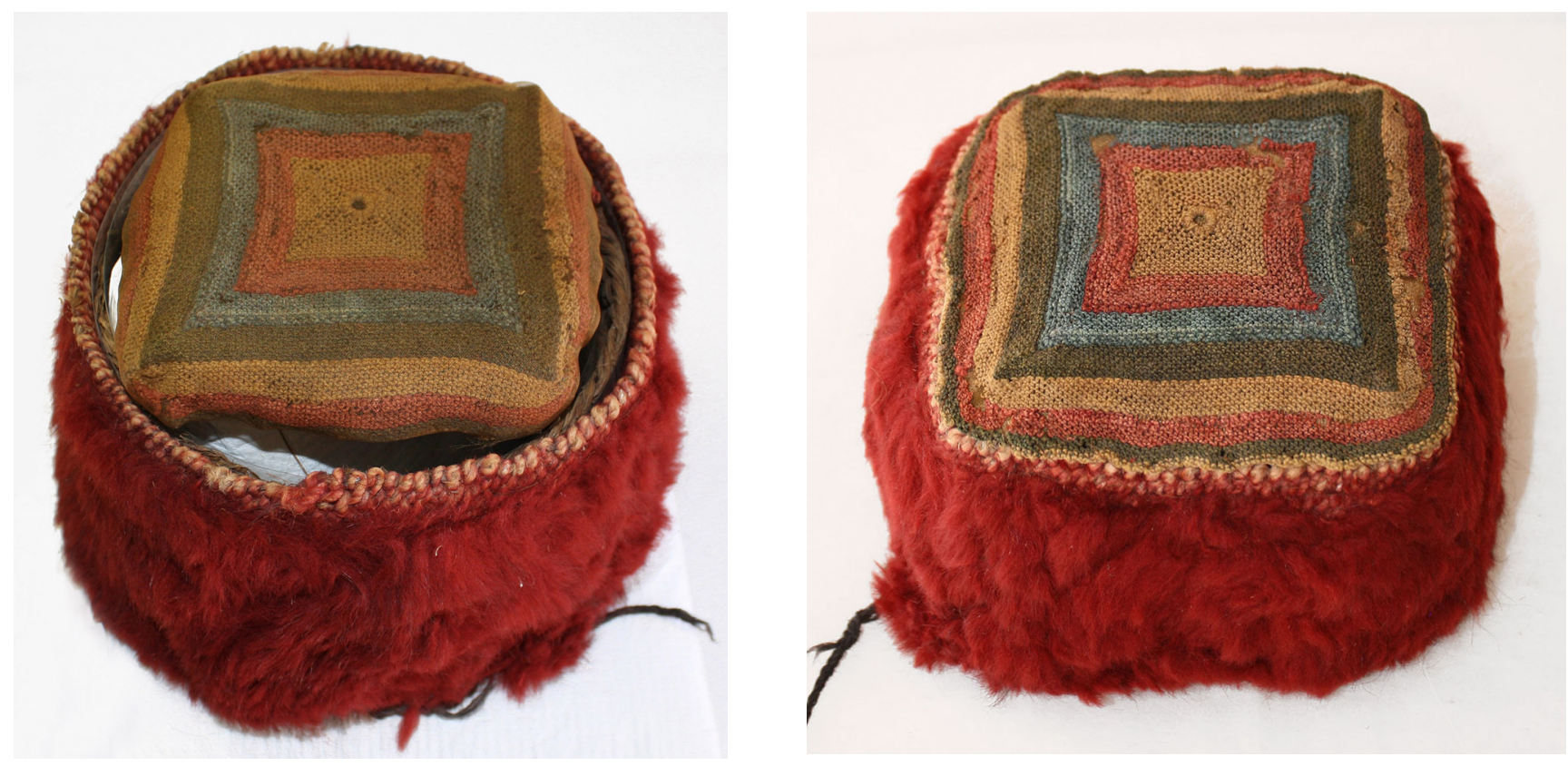

Figuras 21 a y b. Registro fotográfico antes y después de la intervención (Morales 2012).

los orientales en cuanto fueron tejidos con agujas y no en el telar haciendo uso de fibras de camélido.

En cuanto al tratamiento de restauración, se priorizó el respeto a la autenticidad del tocado, por lo que se dedicó un tiempo importante a reflexionar sobre las soluciones que permitieran restituir la legibilidad del artefacto. Además, la intervención anterior generó un aprendizaje en cuanto al uso de materiales de conservación inadecuados para el ambiente árido de San Pedro de Atacama, por ejemplo, el uso del Mylar $^{\circledast}$ para encapsular estructuras textiles y la aplicación de Paraloid ${ }^{\circledR}$ como consolidante de fibras de composición celulósica ya que favorece los cambios de color, brillo y rigidez de las fibras.

Finalmente, este trabajo significó un aporte en cuanto se restauró uno de los tres gorros representativos de una clase que se caracteriza por una banda cefálica anillada con mechas rojas y un cintillo interior vegetal, permitiendo que pudiera ser exhibido en una eventual muestra museográfica de tocados atacameños.

\section{Notas}

[1] Unidades territoriales pertenecientes a un conjunto de individuos relacionados por lazos de parentesco y/o económicos.

[2] El registro fotográfico del individuo estuvo a cargo de WiIliam Conklin (Torres, com. personal, 2012).

[3] No se especifica el tipo de Paraloid usado.

[4] Los valores de H.R. registrados en este proceso se caracterizaron por una progresión y descenso constantes, con una H.R. máxima observada de $93 \%$

\section{Agradecimientos}

El presente trabajo contó con el apoyo del proyecto PIA-CONICYT Anillo ACT No 096 (http://www.cienciaymemoria.cl) y del Instituto de Investigaciones Arqueológicas y Museo R.P. Gustavo Le Paige.

Mis agradecimientos a Hermann M. Niemeyer del Laboratorio de Química Ecológica de la Universidad de Chile por la permanente orientación en torno a los análisis científicos de la pieza y a Maeva Schwend por la asesoría continúa e indispensable respecto al tratamiento de restauración realizado.

A ambos, Hermann y Maeva, agradezco también la revisión del presente manuscrito. A todo el equipo de la Unidad de Colecciones y Conservación del I.I.A.M., en especial a Arturo Torres y a Helena Horta por la permanente colaboración en las actividades involucradas en este proyecto.

\section{Bibliografía}

BERENGUER, J. (2006). Gorros del Desierto. Santiago de Chile: Museo Chileno de Arte Precolombino.

BRAVO, L. y LLAGOSTERA, A. (1986). "Solcor 3: Un aporte al conocimiento de la cultura San Pedro. Período 500 al 900 d.C.." En Chungara 16-17: 323-332.

BRAVO, M. (1993). "Análisis técnico de cinco gorros atacameños". En Identidad y Prestigio en Los Andes. Gorros, turbantes y diademas. Museo Chileno de Arte Precolombino. Santiago, Chile: 76-82. 
HARRIS, J. (2004). 5.000 years of Textiles. Washington: Smithsonian Books.

LATCHAM, R. (1938). Arqueología de la Región Atacameña. Santiago: Universidad de Chile.

LINDBERG, I. (1963). “Tejidos y adornos de los cementerios Quitor 2, 5 y 6 de San Pedro de Atacama". En Revista Universitaria, XLVIII: 195-202.

LLAGOSTERA, A., TORRES, M.C., y COSTA, M.A. (1988). “El complejo psicotrópico en Solcor-3, (San Pedro de Atacama)". En Estudios Atacameños 9: 67-106.

COMITÉ NACIONAL DE CONSERVACIÓN TEXTIL (2002). Manual de conservación preventiva de textiles. Proyecto catastro del patrimonio textil chileno. Santiago de Chile: Comité Nacional de Conservación Textil. Dirección de Bibliotecas Archivos y Museos . Fundación Andes.

OAKLAND, A. (1994). "Tradición e innovación en la prehistoria andina de San Pedro de Atacama" . En Estudios Atacameños 11: 109-120.
NORTON, R. (1990). "Conservation of artifacts made from plant materials". En The conservation of artifacts made from plant materials, Getty Trust Publications: Getty Conservation Institute. California: 195-285.

ROJAS, A.M. y HOCES DE LA GUARDIA, S. (2000). "Coexistencia y diversidad técnica, textural y formal en los textiles de un fardo perteneciente al sitio Coyo de San Pedro de Atacama". En Chungara, 32 (2): 227-233.

SEILER-BALDINGER, A. (1994). Textiles: A classification of techniques. Bathurst, Australia: Crawford House Press.

SINCLAIRE, C. (1998). “Los gorros de cuatro puntas de la colección arqueológica Manuel Blanco Encalada: tipología y secuencia para el Valle de Azapa, Arica". En Boletín del Comité Nacional de Conservación Textil 3: 169-00.

TÍMÁR-BALÁZSY, A. (1999). "Drying behaviour of fibres". Proceedings of the ICOM Committee for Conservation Triennial Meeting (12th), Lyon, 661-666.

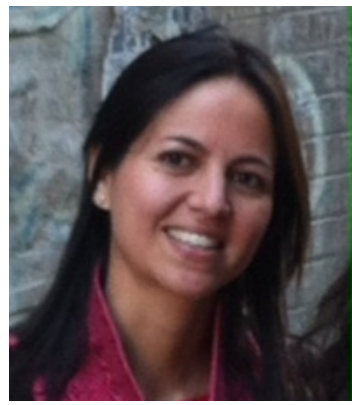

\section{Carolina Morales-Nilo}

Diseñadora, Pontificia Universidad Católica de Chile Postítulo en Restauración del Patrimonio Cultural Mueble, Universidad de Chile carolimorales@gmail.com

Ha sido asesora como diseñadora gráfica y textil en proyectos de investigación FONDECYT en la línea de "Tecnologías textiles precolombinas de los Andes" apoyada por la Escuela de Diseño de la Pontificia Universidad Católica de Chile y el Museo Chileno de Arte Precolombino. Se ha formado en la conservación y restauración de bienes muebles realizando pasantías en el Área de Conservación del Museo Chileno de Arte Precolombino (Santiago) y en el Museo R.P. Gustavo Le Paige (San Pedro de Atacama), dirigiéndolas al área del patrimonio textil etnográfico y arqueológico.

Artículo enviado el 10/08/2013

Artículo aceptado el 07/07/2014 